\title{
The Art and the Science in Winning Public-Sector e-Procurement Contracts particularly by Small and Medium-Sized Enterprises [SMEs]
}

\author{
Keith White-Hunt
}

Philip Norman

Charlotte Norman

\begin{abstract}
:
This paper considers public-sector purchasing in the EU and particularly the UK and how SMEs have benefited and can further do so, from the opportunities presented by e-procurement by addressing its perceived barriers through integrating via this on-line platform, traditional sales and, marketing skills \& experience, together with project management expertise, to successfully bid for contracts. A glossary of terms; and checklist \& discussion of 'dos and don'ts', for SMEs seeking to successfully engage with e-procurement public markets are presented, based on the analysis of numerous case studies.
\end{abstract}

\section{Keywords:}

bid; bid-consultant; bid-writer; bid scoring/contract assessment; contracts; Contracts Finder; EC; e-procurement; EU; good practices; government; ICT; NHS Supply Chain; on-line branding; portals; project management; public-sector procurement; sales \& marketing; SMEs; TED; tender; UK.

\section{A brief background to public e-procurement and the role of SMEs}

United Kingdom [UK] Central Government procurement spending was around £45 Billion (about 51 Billion Euros) in 2015, of which approximately $£ 5$ Billion (5.65 Billion Euros) was placed directly with SMEs ${ }^{1}$. However, all forms of public sector spending for goods and services (by hospitals; universities; local governments, including schools \& colleges; housing bodies; etc.) in the UK exceeded $£ 230$ Billion (260 Billion Euros) annually².

In August 2015, the UK Cabinet Office increased the target for the percentage of government spending to be placed with SMEs, from 25 to 33 per cent, by 2020. The target covers both direct contracts with SMEs and spending that reaches SMEs indirectly (where the government's contract is with a larger provider that subcontracts with SMEs as part of its supply chain).

In 2016, the UK Government's Department for Business, Innovation \& Skills [BIS] estimated there were 5.4 million SMEs in the Country. The definition of an SME followed that of the European Commission: an entity engaged in economic activity employing fewer than 250 people; having annual sales of, or less than, 50 million Euros (£44.26 million); and assets of or less than, 43 million Euros (£38 million). Most were private sector businesses, but the definition included many voluntary, community and social enterprise [VCSE] organizations ${ }^{1}$.

To achieve the target of 33 percent of government spending to be placed with SMEs by 2020, the UK Government has sought to remove some of the barriers that SMEs face when bidding for public sector contracts. Among the constraints identified were the poor visibility of opportunities and burdensome pre-qualification requirements. Therefore, the Government abolished (supplier) prequalification questionnaires for low-value contracts ( $£ 100,000$ or about 113,000 Euros, or less) and required the greater use of e-procurement information systems, such as 'Contracts Finder' (a portal for advertising government tenders, first launched in 2011). Furthermore, the Social Value Act 2012 had already required government bodies commissioning a contract for supply of goods and services, 
to consider wider social, economic and environmental benefits of the procurement process (which in particular, is often thought to benefit VCSEs).

Largely because of the increased use of e-procurement systems, processes, innovations and simplifications discussed above and elsewhere in this paper, SMEs increased their share of the public procurement market in the UK. Public bodies spent £268.3 Billion (about 304 Billion Euros) on goods and services in 2015/16. The proportion of direct spending with SMEs increased from $6.5 \%$ in 2009-10 to $10.9 \%$ in 2014-15. However, by the same year, $£ 4.9$ Billion (about 5.55 Billion Euros) or 27 percent of government spending was received in total by SMEs when indirect spending is included ('indirect' meaning being part of a larger contractor's supply chain to fulfil a government contract) ${ }^{3}$, exceeding its pre-set target of one-quarter (or 25 percent) for this date, by an additional 2 percent.

In 2012, The European Commission put forward a 'communication' to the European Parliament; Council; European Economic and Social Committee [EESC]; and the Committee of the Regions, entitled 'A Strategy for e-procurement'4 which presented the strategic importance of electronic procurement (e-procurement) and set out the main actions through which the Commission intended to support the transition towards full e-procurement in the EU. At that date, the Commission believed that the objective of completing this transition by mid-2016 was feasible (albeit recognising that this would more probably be 2017, given the two years needed for transposition).

The EC's ambitious proposition envisaged that a total of around 100 Billion Euros ( $£ 88$ Billion) could be saved annually from the 2 Trillion Euros ( $£ 1.77$ Trillion) overall public procurement spend across the EC by mandating e-procurement must be used for this purpose. This was to include posting all contract opportunities online, making all tender documents available, the electronic submission of bids and making all communication digital. The target-date for Central government bodies to achieve all this was mid-2014. The wider public sector was to seek to achieve the first two elements by the same date, but mid-2016 was suggested for meeting the communication aspect. The Commission projected it could itself move to full e-procurement of its own purchasing needs by mid2015 .

However, while welcoming the EU's statement as a proper and ambitious objective, the EESC recognised this would represent a massive acceleration in comparison with what had been achieved in the (then) previous eight years. Indeed, the Commission was itself then currently completing a study (due for publication before the end of 2012) to show the level reached in each country, with the average percentage of public e-procurement remaining very low, for example, Italy had achieved only 4 percent. Thus, the EESC emphasised that numerous conditions on such issues of standardization, interoperability and accessibility, etc. would have to be met if such an objective was to be achieved ${ }^{4}$.

In addition to the projected cost savings for government authorities; the European Commission was also seeking to increase transparency and reduce corruption; promote increased integration of EU markets; also supporting SMEs, believing that any new costs associated with implementing bidding for contracts on-line, would quickly be offset by the benefits of greater access to public markets. The EESC highlighted the key contribution that e-procurement can make to transparency in public sector supply processes and to combating fraud ${ }^{4}$. With electronic tools, the entire process can be monitored and assessed, as can suppliers' performance in it. This information is important in ensuring maximum e-transparency in the public sector and can provide a powerful incentive for the adoption of e-procurement tools, especially for SMEs. Interestingly, Portugal provides an example of best practice in this field ${ }^{5}$. 


\section{Opportunities and Constraints to SMEs participation in e-public procurement}

Notwithstanding the above discussion, it is well documented that SMEs have often been particularly disadvantaged when it comes to leveraging Internet \& Communications Technology [ICT] such as e-procurement, to their advantage. SME suppliers with little initial leverage in the market are often reluctant to use e-procurement because they consider that the perceived benefits of participating do not compensate for the perceived investment required. However, it is often simply unfamiliarity with, dislike or distrust of technology that presents a perceived rather than a real barrier to SMEs, which might otherwise benefit from greater access to public sector contracts through increasing use of e-procurement by government buyers and contract commissioners.

ICT may be viewed simply as a means of obtaining easy and up-to-date access to a wide source of contract opportunities now offered through e-procurement systems rather than as previously advertised and disseminated via paper-based and word-of-mouth based systems and simultaneously permitting tenders to be submitted on-line rather than in hardcopy documentation. In addition, SMEs can integrate traditional sales and marketing skills \& experience, together with project management expertise, in responding to e-procurement, particularly as public organisations have vast and varied contract requirements, presenting many sector, country-wide and even international opportunities.

How does a SME identify the opportunities most relevant to its business? A simple and effective way to find appropriate contracts (by type; technology; size; delivery; and payment schedules; etc.) is to make use of the online portals set up to allow an organization to search for public sector tenders. These usually allow a business to enter specific search terms and key information relevant to them, such that currently listed contract opportunities that match the criteria will then be pulled out of the data-base being accessed.

\section{On-line portals for e-public procurement}

Among the most well-known portals used in the UK to access public sector business are:

'Contracts Finder', a free-access service (https://www.gov.uk/contracts-finder). Constituent parts of the UK i.e. Scotland, Wales and Northern Ireland have their own dedicated public-sector procurement websites. These are: 'Public Contracts Scotland' (https://www.publiccontractsscotland.gov.uk/search/search_mainpage.aspx) for opportunities with public sector bodies in Scotland; 'Sell2Wales' (https://www.sell2wales.gov.wales/) for opportunities with public sector bodies in Wales; and 'eSourcing NI' (https://esourcingni.bravosolution.co.uk/web/login.shtml) for opportunities with public sector bodies in Northern Ireland.

Tenders Electronic Daily [TED] (https://data.europa.eu/euodp/en/data/dataset/ted-1). TED is the 'Supplement to the Official Journal of the EU [OJS] providing information on public procurement contracts, according to the EU rules on public procurements, of notices published in EU Member States, the European Economic Area (EEA) and beyond. Users can browse, search and sort procurement notices by country, region, business sector, etc.

NHS Supply Chain (https://www.supplychain.nhs.uk/). NHS Supply Chain is an organisation run by DHL Supply Chain (a division of Deutsche Post DHL) on behalf of NHS Business Services Authority, the role of which is to provide a dedicated supply chain to the National Health Service [NHS] in England.

Procontract (https://procontract.due-north.com/). This is a portal developed by PROACTIS Holdings PLC, a UK company, which is a Spend Control and e-Procurement solution provider. 
Additionally, there are numerous fee-charging portals, as well as dedicated regional and in-house procurement portals; some free, some fee and some subscription.

Opportunities vary hugely but a wide range of different businesses benefit from winning public sector contracts each year. Of course, 'to win it you have to be in it' so a company has nothing to lose by registering with a free portal and just looking at what opportunities present themselves.

\section{Project management of the e-public procurement tendering process}

Once an opportunity has been identified, a company needs to put the appropriate planning in place from an early stage to ensure that it maximizes its chances of making a successful bid. Effective early engagement with and profiling of the potential customer are essential. The tender should be treated as a project, putting in place effective project management tools and key milestones, to measure and ensure the smooth running of the process. Investing time at this stage will pay off in the longer term, particularly if competitors are more complacent about the process.

It is important to make sure the right people are involved in the project and that they are fully committed: whether this means using in-house employees or investing in outside help if there is a knowledge gap. If there is not the right combination of skill-sets working on the bid, valuable knowledge and experience may be omitted that could result in the loss of the contract. There are now professional firms of 'Bid-Consultants' and dedicated 'Bid-Writers' who have seen hundreds of different types of tenders (and whose expertise will often include having assessed bids) that will often know exactly what information needs to be included in a bid and how the bid needs to be written to gain the highest possible 'score' (assessment) for each section of the tender. Investing time and money in this type of expertise (whether employing specialists in-house or buying-in on a contract-to-contract basis) can really pay off and place a company well ahead of its competitors.

It is also important to ensure support from sufficiently high up in the company management, otherwise there may be insufficient resource allocation, or necessary personnel may not take a project as seriously as they should, to achieve success.

When it comes to completing the tender documentation, a company must ensure that it is wellprepared, develops a project plan and sticks to it. One key piece of advice which any good bidconsultant would tell a client is to find out exactly what the buyer is looking for in response to their tender and, for the client not to assume that it knows what the customer wants. This information is usually laid out within the original specifications of the tender document, but if there is any doubt there is no reason a supplier cannot request further clarification from the buying organization (this is NOT soliciting or badgering). Indeed, most 'live' tenders have a function allowing the asking of questions within pre-determined timeframes. Sensible and appropriate questions aimed at providing a more precise or cost-effective solution also allow a good opportunity to influence and raise supplier credibility with the buyer, so it can be invaluable.

Writing a bid should not always be allocated to only one person within an organisation, nor to someone who simply appears to have the time available to do it. This is unlikely to provide the right person for the job; or build-up in-house expertise: not to mention increasing an organization's commercial vulnerability. The individual who takes primary responsibility for executing the bid must be able to write well, be grammatically coherent, intimately understand the business, as well as the customer and the specific needs of the contract! The right in-house employees who are experts on technical details pertaining to the contract should be involved for specific aspects of the tender, or it may even be necessary to engage experts from outside, to feed into the writing of the bid.

Once the tender document is complete, it is essential that it is thoroughly checked, line-by-line, word-by-word and to have more than one party do so. The document must be submitted on time 
in accordance with the tender schedule and preferably 24 hours before the final deadline: if it is late it will not be considered. All necessary supplemental documents, evidence, blueprints, plans, photographs, etc. as appropriate, should be submitted at the same time.

After submission, it is necessary to wait for the 'decision of intended award outcome' to find out the party that has won the contract. The timescale for the evaluation process is usually published well in advance. The final announcement will be made online and a company may also receive a letter to inform whether a bid has been successful or not.

The customer will communicate with the successful bidder when it is ready to move the process forward. An unsuccessful bidder may be able to find out why they were unsuccessful, if for instance, this was decided by anything other than having submitted the most competitive price. This can help a company be more successful in tailoring its on-line bidding in the future and there is generally no harm in an appropriate and politely-worded request. Of course, a response may not always be forthcoming. Occasionally, it is possible to challenge a decision, but only if there are genuine, sufficient and transparent reasons for doing so.

\section{Two Case studies of successful e-procurement by SMEs}

The following two case studies from the UK illustrate how SMEs can leverage e-procurement technology and markets to their advantage:

A small creative agency based within 20 miles of central London had been supplying services to the British Broadcasting Corporation [BBC] for several years, for exhibition stand design; branding for $\mathrm{BBC}$ projects; and graphics for public areas within $\mathrm{BBC}$ buildings and studios. However, when the company's contract expired, it was required to bid via an e-procurement platform; if not successful it would lose a valuable and prestigious customer that it had spent years nurturing. The agency brought in the assistance of a professional firm of Bid-Consultants which first spent time to develop a good understanding of the agency's business; corporate culture; and service offering, before turning attention to working with its own personnel to draft the tender response to the BBC response, which was first thoroughly checked by the senior management team of both parties, before submission. Not only was the bid successful and the contract reinstated, thereby safeguarding its incumbent business, but further exciting opportunities opened to supply additional services to the BBC, including being able to develop further projects with them under a contracting partnership.

A small janitorial company based in the south-west of England serviced a wide variety of public and private sector organisations within its immediate region and its contracts varied greatly in size. It had established a reputation for providing reliable and customer-tailored staff, but it wanted to build a more sustainable business over a wider area by winning public sector contracts, particularly for educational establishments. The company had neither time, resources, nor in-house skills to pursue e-procurement public sector bids. However, it approached a bid-consultant that tailored provision of its support in line with the company's timelines and budget that resulted within a few years to winning over $£ 600,000$ in contracts, for a tiny fraction of this amount in fees for bought-in expertise; demonstrating that even a modest, but nevertheless sensible investment in the bidding process, can produce significant return. The bid-consultant guided the company so that it became able to produce its own successful public-sector bids based on the model it initially proposed after studying its business. While the company and the bid-consultant continue to have a productive relationship, this successful example of knowledge-transfer, means that it now only provides specialist advice (if required) including reviewing some more complex bids, before these are presented to the customer. 


\section{Good Practices in e-procurement: 'dos and don'ts'}

The above examples and many more of which the authors have direct or indirect experience, have allowed the formulation of a checklist of 'good practices' that companies and SMEs particularly, can follow to successfully address e-procurement opportunities. Using more commercial terms, these may be labelled 'dos and don'ts':

Figure 1: 'Dos and Don'ts' for Successful e-procurement Bids

- $\quad$ Do complete the tender in full, do what is asked and avoid sending stock corporate sales material and standard copy;

- Do not ignore the word count or fail to fill in any part of the tender and if asked to complete the tender in a certain format then do so;

- Do hire a consultant to help complete a bid if in-house personnel do not have the time or experience;

- $\quad$ Do not include bold statements that cannot be backed up with the appropriate evidence;

- Do enter a dialogue with the buyer if any aspects of the tender are unclear (the tender document will usually provide instructions for such communication);

- Do not forget to inform nominated referees, as this may otherwise end up giving a poor or the wrong impression to the buyer;

- Do be creative and work out the company's unique selling point and make the response relevant to the requirement;

- Do not submit the tender late and, if possible, send it off 24 hours prior to the deadline.

- $\quad$ Do price at a point which is sustainable for the bidding company.

\section{Understanding common terms used in e-procurement: 'Jargon Buster'}

Often when entering into new markets, companies and particularly SMEs, may be daunted by encountering terms and conditions with which they are not familiar. However, e-procurement lends itself to little that is new in this regard and which will not be familiar to manual or paper-based tendering procedures. From the authors' direct or indirect experience of multiple e-procurement tenders, an explanation of many of these terms is provided below. Again, using more commercial language, this may be called a 'Jargon Buster':

Figure 2: 'Jargon Buster' for Understanding e-procurement Bids

- Award Criteria - evaluation criteria used to inform and evidence the decision-making by which a candidate supplier can be awarded a specific contract;

- Clarifications - these are (written) discussions with candidates or tenderers to clarify or supplement the content of tenders or the requirements of the contracting authority and they must not involve discrimination (i.e. the clarification must be circulated to all relevant parties);

- Contract Notice - a notice, published via OJEU (see below) to inform the EU market of an opportunity to win a contract;

- Contract Award Notice - a notice, published via OJEU, to inform the EU market of which contract was awarded to which supplier;

- Contracts Finder - this is the system, where all new UK Government contract opportunities can be found;

- Evaluation Criteria - high level selection and award criteria found in the PQQ and/or the ITT (see below); it may be broken down into more detailed sub-criterion; 
- Expression of Interest [EOI] - an expression of interest is a formal notice to potential suppliers that a prospective buyer is planning to acquire goods or services and inviting interested suppliers to register their interest;

- $\quad$ Framework Agreement - a general term for agreements with one or more providers that set out terms and conditions under which specific purchases ('call-offs') can be made throughout the term of the agreement (often 4 years);

- Invitation to Tender [ITT] - a call for bids or call for tenders or invitation to tender (ITT) (often called tender for short) is a special procedure for generating competing offers from different bidders looking to obtain an award of business activity in works, supply, or service contracts and are sometimes preceded by a pre-qualification questionnaire $[\mathrm{PQQ}]$ where allowed;

- Most Economically Advantageous Tender [MEAT] - factors other than or in addition to price, such as quality, technical merit and running costs can be considered, this is the evaluation option other than lowest price;

- $\quad$ OJEU - Official Journal of the European Union;

- Pre-Qualification Questionnaire [PQQ] - the PQQ is a tool used as the first part of a two-stage procurement process to enable public sector procurers to identify the most suitable suppliers to invite to tender (or quote) for contracts in the second part of a two-stage procurement process;

- Selection Criteria - evaluation criteria and sub-criterion used to inform and evidence, decisionmaking on reducing the quantity of candidate supplier(s) to pass through to next stage selection that will be based on award criteria;

- Specification - a document contained within a contract setting out clearly the client's specific requirements for the goods, services or works in question, see also Input Specification (performance) and Output Specification (technical);

- Standstill Period (sometimes known as the Alcatel Period) - a set period (usually 10-calendar days) prior to the award stage to permit unsuccessful tenderers to seek further information about the award decision and enable them to take legal action where they have sufficient grounds;

- Whole-life Cost [WLC] - the total cost of investing in an asset, evaluated by considering not only the initial outlay, but also all the costs of owning, operating and disposing of that asset.

\section{Sales and Marketing in e-procurement}

As with sales and marketing in general, there are different techniques and tactics a company can use to ensure an e-procurement bid scores well in assessment, but once a winning formula is discovered it can be successfully applied to bid for more contracts with different public bodies. There are over 50,000 registered public bodies in the UK, let alone the EU and the procurement process they are legally required to follow is more-or-less the same, so by default, the tender process will be too $^{6}$. Using an experienced bid writer (whether a bought-in consultant or in-house specialist) will generally see 'win-rate' soar. As referenced above, for a SME new to the process, buying-in expertise can provide a framework to grow in-house expertise in tendering and even to developing a highly recognizable and trustworthy on-line brand for responding to e-procurement contracts.

Finally, what of the quite common view among many SMEs that 'the current supplier nearly always retains a repeat (or is awarded a new but similar) contract? While it is true that if an incumbent supplier has met the service-level agreement $[\mathrm{SLA}]^{7}$ and Key Performance Indicators $[\mathrm{KPIs}]^{8}$ of the contract, they are in a strong position to re-tender, there is no guarantee they will be successful. Because of the principles of fair and open competition, public contracts must be re-tendered on a level playing field and in the UK, only $35 \%$ of public contracts are retained by the incumbent supplier. 
Of course, the corollary is how does an SME leverage its advantage if it is already the incumbent supplier? There is an enormous amount that can be done to influence the re-tender requirement and specification by focusing on winning themes: drawing upon the successes delivered in the current contract, highlighting continuous improvement initiatives and emerging technologies that will add value and, most importantly, reminding the customer what has been achieved, what might be lost and even more so, what risks may be engendered by awarding a contract to a new supplier. The challenge is including this within the confines of a prescriptive and standard public tender, often with a restricted word or character count. Responding to this challenge is worthwhile as it is usually more profitable to retain business than try to replace it, of course, this does not preclude growing new business.

\section{Conclusion: e-procurement by SMEs is critical to national economies}

At the start of 2015, there were 5.4 million businesses in the UK. Over $99 \%$ of these were SMEs. Of these, most were micro-businesses, employing fewer than ten people ${ }^{9}$. The Office for National Statistics estimates that SMEs create around $£ 35$ of gross value added to the UK economy for every $£ 100$ of turnover, while larger companies only create around $£ 24^{10}$. Thus SMEs are very important for the UK (as well as the EU) economy and their role in delivering public contracts and thus their increased ability to participate in e-procurement is critical. The lesson is clear: for SMEs to optimise their response to public sector e-procurement, it is not enough to see this just as the need to improve the application of ICT or administrative platforms and regulations, but the integration of sales and marketing skills \& experience, together with project management expertise, is essential.

\section{References}

1 'Government's spending with small and medium-sized enterprises', UK National Audit Office, London, 7 March 2016; accessible on-line at:

(https://www.nao.org.uk/wp-content/uploads/2016/03/Governments-spending-with-small-andmedium-sizes-enterprises.pdf)

2 '2010 to 2015 government policy: government buying' (Policy Paper), Gov.UK, London, 8 May 2015; accessible on-line at:

(https://www.gov.uk/government/publications/2010-to-2015-government-policy-governmentbuying/2010-to-2015-government-policy-government-buying)

${ }^{3}$ Rutter, T. and Trendall, S. 'SMEs still being shut out as half of Whitehall spend goes on megadeals', Public Technology.net, 23 August 2017; accessible on-line at:

(https://www.publictechnology.net/articles/news/smes-still-being-shut-out-half-whitehall-spendgoes-mega-deals-report-claims)

${ }^{4}$ Opinion of the European Economic and Social Committee on the 'Communication from the Commission to the European Parliament, the Council, the European Economic and Social Committee and the Committee of the Regions - A strategy for e-procurement', COM (2012) 179 final, accessible on-line at:

(http://eur-lex.europa.eu/legal-content/EN/TXT/?uri=CELEX:52012AE1715)

5 (http://www.base.gov.pt/Base/pt)

${ }^{6}$ Unfortunately, a corruption-free and level playing-field does not yet seem to be in operation for all public procurement across the whole of the EU. Based on the Tenders Electronic Daily [TED] database archive of over 4 million purchases made by EU Member governments over the previous 
decade, by 2015, 30 percent of calls for tenders received only one bid and the median number of bids per tender had fallen from five to three. SMEs were often losing out to large corporations and national suppliers frequently received favourable discrimination vis-à-vis international bids. For example, see: 'Procurement Spending: Rigging the Bids - Government contracting is growing less competitive, and often more corrupt', The Economist, 19 November 2016. However, this is a subject for a separate paper.

7 The service-level agreement [SLA] is part of a contract between a service provider and its internal or external customers that documents what services the provider will furnish and defines the performance standards the provider is obligated to meet.

${ }^{8}$ A Key Performance Indicator $[\mathrm{KPI}]$ is a measurable value that demonstrates how effectively a company is achieving key objectives i.e. pre-determined targets, in its contract delivery.

${ }^{9}$ UK Department for Business, Innovation \& Skills, Business, 'Population Estimates for UK and the Regions', 2015.

${ }^{10}$ UK Office for National Statistics, 'Annual Business Survey', 2013. 